\title{
Efektivitas Bio Herbisida Pulp Kakao (Theobroma cacao L) Dengan Beberapa Tingkat Kematangan Fermentasi Terhadap Pengendalian Gulma di Perkebunan Kelapa Sawit (Elaeis guineensis Jacq)
}

\author{
${ }^{(1)}$ Aulia Juanda DJS, S.Si., M.Si, ${ }^{(2)}$ Saroha Manurung, SST., M.P, ${ }^{(3)}$ Yasser Subroto Ginting \\ STIPER Agrobisnis Perkebunan (STIPAP) ${ }^{(1)}$, STIPER Agrobisnis Perkebunan (STIPAP) ${ }^{(2)}$, Mahasiswa \\ STIPER Agrobisnis Perkebunan (STIPAP) ${ }^{(3)}$
}

Aulia_juanda@stipap.ac.id ${ }^{(1)}, \underline{\text { saroha@ }}^{\text {stipap.ac.id }}{ }^{(2)}$

\begin{abstract}
ABSTRAK
Bioherbisida dari pulp kakao merupakan salah satu produk sampingan dari kakao, yang masih belum dimanfaatkan secara optimal. Berdasarkan hasil tes awal, fermentasi cair pulp kakao berpotensi untuk digunakan sebagai bio-herbisida. Penelitian ini bertujuan untuk mengetahui pengaruh pengaruh lama fermentasi bioherbisida pulp kakao untuk mengendalikan gulma. Penelitian ini dilakukan di area perkebunan kelapa sawit kampus Lembaga Pendidikan Perkebunan (LPP) Medan. Penelitian dilakukan pada bulan Mei dan Juli 2016. Penelitian ini menggunakan Rancangan Acak Kelompok (RAK) non faktorial, terdiri dari 4 perlakuan dan diulang 3 kali. Parameter pengujian disusun pada daftar varians dan menguji Least Significant Difference (LSD) pada level 5\% dan 1\%. Hasil penelitian menunjukkan bahwa bioherbisida pulp kakao mengandung asam asetat yang dapat meracuni gulma. Persentase keracunan gulma tertinggi dalam 3 Hari Setelah Aplikasi (HSA) tingkat persentase toksisitas 26,00\% MI, MII 30,00\%, dan sebesar 31,00\% MIII. Ini menunjukkan bahwa lama fermentasi mempengaruhi jumlah kandungan asam cuka untuk setiap perawatan. Toksisitas yang disebabkan oleh bioherbisida pulp kakao adalah herbisida kontak seperti yang terlihat dari permukaan daun yang layu tampak seperti terbakar, bagian yang terkena dampak fermentasi air limbah pulp kakao.
\end{abstract}

Kata Kunci : fermentasi, pulp kakao, bio-herbisida

\begin{abstract}
Bio herbicide cocoa pulp is one byproduct of the management of cocoa, which still has not been utilized optimally. Based on initial test results, the liquid fermentation of cocoa pulp has the potential to be used as a bio-herbicide. This study aims to determine the effect of cocoa pulp bio-herbicide weed control and influence of the old cocoa pulp bio herbicides to control weeds. This research was conducted in the area of oil palm plantations campus Educational Institution (LPP) Medan. When the study was conducted in May and July 2016. The study used randomized block design (RAK) non factorial, consisting of 4 treatments and repeat 3 times. Testing parameters are arranged on the list of variance and test the Least Significant Difference (LSD) at the level of $5 \%$ and $1 \%$. The results showed that herbicide bio cocoa pulp contains acetic acid which can poison weeds. The percentage of weed poisoning is highest in 3 Days After Application (HSA) where the percentage level of toxicity of $26.00 \%$ MI, MII of $30.00 \%$, and amounted to $31.00 \%$ miii. This indicates that the length of fermentation affect the amount of the acid content of vinegar for each treatment. The toxicity caused by herbicide bio cocoa pulp is contact as seen from the patches and burning of weeds affected part fermenting cacao pulp wastewater
\end{abstract}

Keywords : fermentation, cocoa pulp, bio-herbicide 
Aulia J, Saroha M, Yasser Subroto G: Efektivitas Bio Herbisida (Theobroma cacao L) Dengan Beberapa Tingkat Kematangan Fermentasi Terhadap Pengendalian Gulma di Perkebunan Kelapa Sawit (Elaeis guineensisJacq)

\section{PENDAHULUAN}

\section{Latar Belakang}

Gulma adalah tumbuhan yang tumbuhnya salah tempat. Sebagai tumbuhan, gulma selalu berada di sekitar tanaman yang dibudidayakan dan berasosiasi dengannya secara khas. Karena luasnya penyebaran, gulma mempunyai berbagai nama sesuai dengan asal daerah dan negaranya seperti Weed (Inggris), Unkraut (Jerman), Onkruit (Belanda), dan Tzao (Cina), serta banyak nama lainnya (Moenandir, 1993). Keberadaan gulma dengan jumlah populasi cukup tinggi mengakibatkan kerugian besar bagi manusia sehingga perlu dikendalikan. Pengendalian gulma dapat dilakukan secara preventif, manual, kultur teknis, biologi, hayati, terpadu, dan atau secara kimia dengan menggunakan herbisida. Pengendalian gulma dengan cara menggunakan herbisida kimia banyak diminati terutama untuk lahan pertanian yang cukup luas. Hal tersebut dikarenakan herbisida kimiawi dapat mengendalikan gulma sebelum mengganggu, mengendalikan gulma pada tanaman kelapa sawit, mencegah kerusakan tanaman kelapa sawit, lebih efektif membunuh gulma tanaman tahunan dan semak blukar, dan meningkatkan hasil panen pada tanaman kelapa sawit dibandingkan dengan penyiangan biasa (Sukman dan Yakup, 2002). Namun, penggunaan herbisida secara terus menerus dapat memberikan dampak negatif bagi lingkungan yaitu terjadinya keracunan pada organisme non target, polusi sumber-sumber air dan kerusakan tanah, juga keracunan akibat residu herbisida pada produk pertanian (Genowati dan Suwahyono, 2008). Dengan semakin meningkatnya kesadaran masyarakat akan pentingnya kelestarian lingkungan, maka semakin meningkat pula tuntutan masyarakat akan proses usaha tani yang ramah lingkungan dan produk pertanian yang lebih aman. Salah satu alternatif usaha pengendalian gulma pertanian dan perkebunan adalah menggunakan bio herbisida. Bio herbisida adalah suatu jenis herbisida yang bahan aktifnya berasal dari makhluk hidup. Dalam penelitian ini penulis mencoba memanfaatkan limbah tanaman kakao yang dapat dimanfaatkan sebagai bio herbisida. Tanaman kakao (Theobroma cacao L.) merupakan salah satu komoditas eksport non migas Indonesia, baik sebagai sumber penghidupan bagi petani produsen maupun penyumbang devisa negara dari subsektor perkebunan. Sejauh ini, kakao dimanfaatkan sebagai bahan penyedap yang digunakan untuk produksi makanan, kue, minuman, bahan kosmetik dan sumber lemak nabati (Sunarto, 1992). Proses pemanfaatan pulp kakao belum banyak diketahui oleh masyarakat secara umum, sehingga sering terjadi permasalahan limbah pada saat proses pengolahan awal kakao. Melalui kasus ini, maka dilakukan penelitian dengan memanfaatkan limbah pulp kakao untuk menghasilkan bio herbisida berbahan alami yang tentunya sangat bermanfaat sebagai herbisida yang ramah lingkungan.

\section{Perumusan Masalah}

Percobaan ini dilakukan untuk menjawab urgensi penelitian yang dirumuskan dalam pertanyaan sebagai berikut:

1. Bagaimana pengaruh bio herbisida pulp kakao terhadap pengendalian gulma?

2. Bagaimana pengaruh lama bio herbisida pulp kakao terhadap pengendalian gulma?

\section{Tujuan Penelitian}

Berdasarkan latar belakang dan urgensi penelitian, maka disusun tujuan khusus sebagai berikut:

1. Mengetahui pengaruh bio herbisida pulp kakao terhadap pengendalian gulma.

2. Mengetahui pengaruh lama bio herbisida pulp kakao terhadap pengendalian gulma 
Aulia J, Saroha M, Yasser Subroto G: Efektivitas Bio Herbisida (Theobroma cacao L) Dengan Beberapa Tingkat Kematangan Fermentasi Terhadap Pengendalian Gulma di Perkebunan Kelapa Sawit (Elaeis guineensisJacq)

\section{Manfaat Penelitian}

Adapun manfaat yang menjadi target temuan dalam penelitian ini adalah sebagai berikut:

1. Adanya pengaruh bio herbisida pulp kakao terhadap pengendalian gulma.

2. Adanya pengaruh lama bio herbisida pulp kakao terhadap pengendalian gulma

\section{METODE PENELITIAN}

\section{Tempat dan Waktu}

Penelitian dilakukan pada areal perkebunan kelapa sawit kampus Lembaga Pendidikan Perkebunan (LPP) Medan. Waktu penelitian dilakukan pada bulan Mei sampai dengan Juli 2016.

\section{Desain/Rancangan Penelitian atau Model}

Penelitian menggunakan Rancangan Acak Kelompok (RAK) non faktorial. Yang terdiri dari 4 perlakuan dan ulangan sebanyak 3 kali.
K : Kontrol
MI : Fermentasi I minggu
MII : Fermentasi II minggu
MIII : Fermentasi III minggu

\begin{tabular}{|c|c|c|c|c|}
\hline Ulangan & K & MI & MII & MIII \\
\hline 1 & KI & MI1 & MII1 & MIII1 \\
\hline 2 & KII & MI2 & MII2 & MIII2 \\
\hline 3 & KIII & MI3 & MII3 & MIII3 \\
\hline
\end{tabular}

Jumlah perlakuan : 4 petakan.

Jumlah ulangan : 3 ulangan.

Jumlah plot penelitian: 12 petakan.

Jarak antar plot $\quad: 50 \mathrm{~cm}$.

Panjang plot $\quad: 2 \mathrm{~m}$.

Lebar plot $\quad: 1 \mathrm{~m}$.

Data hasil penelitian di analisis dengan Percobaan Non Faktorial dengan Rancangan Acak

Kelompok (RAK), berdasarkan model linier sebagai berikut :

$\mathrm{Y}_{\mathrm{ij}}=\mu+\mathrm{T}_{\mathrm{i}}+\mathrm{B}_{\mathrm{j}}+\sum_{\mathrm{ij}}$.

$\mathrm{Y}_{\mathrm{ij}}=$ Hasil pengamatan dari faktor pemberian fermentasi limbah cair pulp kakao pada taraf ke-i dan ulangan ke-j.

$\mu=$ Efek dari nilai tengah.

$\mathrm{T}_{\mathrm{i}}=$ Pengaruh perlakuan fermentasi limbah cair pulp kakao.

$\mathrm{B}_{\mathrm{j}} \quad=$ Pengaruh ulangan pada taraf ke-j.

$\sum_{\mathrm{ij}}=$ Pengaruh galat dari faktor pemberian fermentasi limbah cair pulp kakao pada taraf ke-i dan ulanangn ke-j.

Untuk melihat pengujian terhadap parameter yang diamati pada akhir penelitian Daftar Sidik Ragam (DSR) berdasarkan data yang diperoleh terhadap perlakuan yang dipengaruhi nyata dilakukan uji Beda Nyata Terkecil (BNT) dengan taraf 5\% dan 1\%.

\section{Bahan dan Peralatan}

Bahan-bahan yang digunakan dalam penelitian ini adalah cairan fermentasi pulp kakao, dan gulma yang berada di lapangan.

Alat-alat yang digunakan adalah knapsack sprayer, nozzle biru, meteran, cangkul, tali raffia, ember, gelas ukur, dan parang. 
Aulia J, Saroha M, Yasser Subroto G: Efektivitas Bio Herbisida (Theobroma cacao L) Dengan Beberapa Tingkat Kematangan Fermentasi Terhadap Pengendalian Gulma di Perkebunan Kelapa Sawit (Elaeis guineensisJacq)

\section{Tahapan Penelitian}

1. Persiapan areal

Areal penelitian akan dilaksanakan di gawangan mati tanaman kelapa sawit, areal dibersihkan dari sampah dan sebagainya.

2. Pembuatan petak percobaan

Diukur petak percobaan dengan luas $1 \mathrm{~m}$ X $2 \mathrm{~m}$ untuk setiap perlakuan dengan cara dipacak dan dibatasi dengan tali rafia.

3. Identifikasi jenis gulma

Diidentifikasi gulma-gulma yang tumbuh pada petak percobaan sebelum aplikasi bioherbisida. Dihitung identifikasi gulma dengan melakukan pengamatan secara visual. Berikut hasil identifikasi gulma pada petak penelitian

\section{HASIL DAN PEMBAHASAN}

Tabel 3.1 Persentase gulma pada petak penelitian

\begin{tabular}{|l|r|r|}
\hline \multicolumn{1}{|c|}{ Jenis Gulma } & \multicolumn{1}{c|}{ Populasi } & Indeks (\%) \\
\hline Asystasia intrusa (Rumput ganda rusa) & 623 & 38,77 \\
\hline Mikania micrantha(Sembung rambat) & 65 & 4,04 \\
\hline Paspalum Conjugatum (Genjoran, Telur setandu) & 134 & 8,34 \\
\hline Euphorbia heterophylla & 37 & 2,30 \\
\hline Phyllanthus amarus(Meniran) & 63 & 3,92 \\
\hline Axonopus compressus (Rumputpahit) & 273 & 16,99 \\
\hline Cyclosorus aridus (Pakis kadal) & 93 & 5,79 \\
\hline Cyperus kyllingia (Rumput kenop) & 83 & 5,16 \\
\hline Setaria palmifolia (Rumput palem) & 153 & 9,52 \\
\hline Lain-lain & 83 & 5,16 \\
\hline Total & 1607 & 100,00 \\
\hline
\end{tabular}

Berikut adalah gambar hasil identifikasi gulma pada petak-petak penelitian.

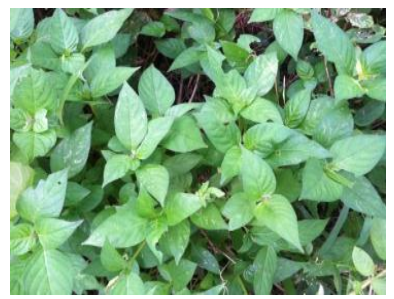

Asystasia intrusa

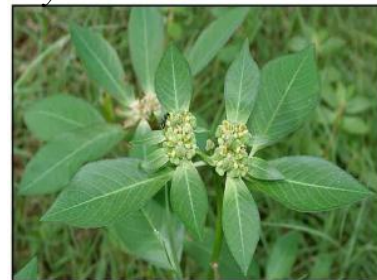

Euphorbia heterophylla

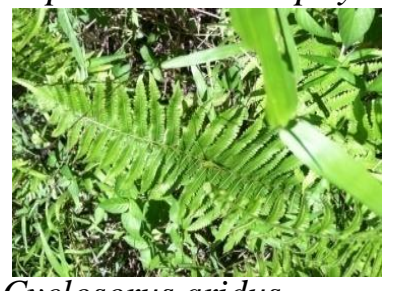

Cyclosorus aridus

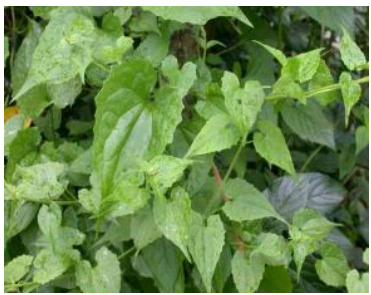

Mikania micrantha

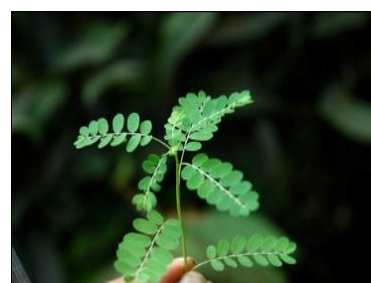

Phyllanthus amarus

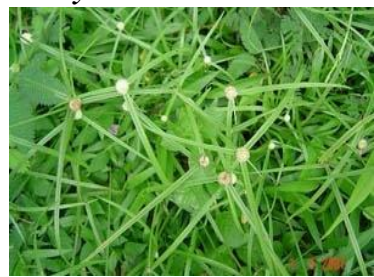

Cyperus kyllingia

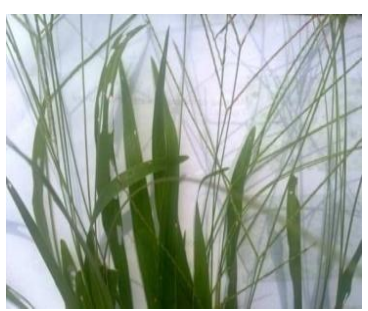

Paspalum Conjugatum

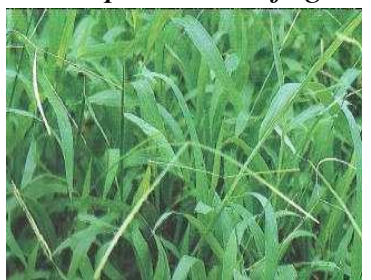

Axonopus compressus

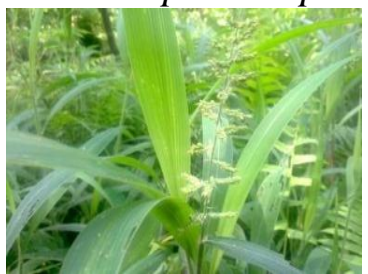

Setaria palmifolia

Gambar 3.1 Hasil identifikasi gulma pada petak-petak penelitian sebelum aplikasi 
Aulia J, Saroha M, Yasser Subroto G: Efektivitas Bio Herbisida (Theobroma cacao L) Dengan Beberapa Tingkat Kematangan Fermentasi Terhadap Pengendalian Gulma di Perkebunan Kelapa Sawit (Elaeis guineensisJacq)

\section{Pembuatan bio herbisida pulp kakao}

Proses pengambilan cairan fermentasi pulp kakao diawali dengan memetik buah kakao di lahan yang siap panen. Buah kakao yang sudah dipetik dikumpulkan di tempat yang kering dan bersih. Kemudian dilakukan pemecahan, pemecahan atau pembelahan buah kakao untuk mendapatkan biji kakao, pemecahan buah kakao harus dilakukan secara hati-hati, agar tidak melukai atau merusak biji kakao. Pemecahan buah kakao dapat mengguanakan pemukul kayu atau pisau. Biji kakao dikeluarkan lalu dimasukan dalam karung goni yang bersih,sedangkan empulur yang melekat pada biji dibuang.Setelah biji kakao semua tertampung di dalam karung goni kemudian karung goni di ikat, digantung dan dilapis plastik agar cairan pulp kakao mengalir dari karung ke plastik. Cairan kakao tersebut dimasukan kedalam jirigen ditutup rapat dan disimpan agar mengalami fermentasi secara alami. Pengambilan cairan fermentasi buah kakao dilakukan tiap minggunya sebanyak tiga kali.

\section{Aplikasi bioherbisida}

Aplikasi bioherbisida dilakukan sekali selama penelitian. Alat yang digunakan adalah knapsack sprayer. Sebelum diaplikasikan alat semprot dikalibrasi terlebih dahulu. Waktu aplikasi pada pagi hari pukul 07.00 sampai 09.00 WIB. Aplikasi bioherbisida dilakukan dengan membuat sungkup dari plastik yang akan diletakan di pinggir atau di pembatas-pembatas petak percobaan, penggunaan sungkup ini dilakukan agar bioherbisida yang diaplikasikan tidak menyebar ke petak percobaan lain dan menghindari bias.

\section{Pengamatan dan Indikator}

Pengamatan tingkat keracunan gulma dilakukan secara visual setiap hari selama tujuh hari setelah aplikasi bio herbisida pulp kakao dengan sistem penilaian skoring atau taksiran persentase (Komisi Pestisida, 2000) sebagai berikut:

1. $0=$ Tidak ada keracunan $0-5 \%$ bentuk atau warna daun tidak normal.

2. $1=$ Keracunan ringan, $5-10 \%$ bentuk atau warna daun tidak normal.

3. $2=$ Keracunan sedang $>10-20 \%$ bentuk atau warna daun tidak normal.

4. $3=$ Keracunan berat $>20-50 \%$ bentuk atau warna daun tidak normal.

5. $4=$ Keracunan sangat berat $>50 \%$ bentuk atau warna dauntidak normal hingga mengering, rontok, dan tanaman mati.

Indikator hasil pengamatan : Mengamati bentuk fisik gulma setelah aplikasi bioherbisida. Gulma yang bertahan hidup adalah gulma yang masih tampak kelihatan segar, sedangkan gulma yang keracunan adalah tampak kelihatan tidak segar, dengan kata lain secara visual berwarna kuning, kuning kecoklatan.

\section{Bagan Alur Penelitian}

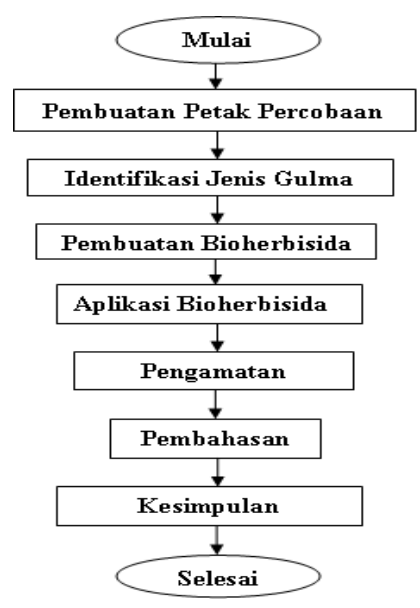


Aulia J, Saroha M, Yasser Subroto G: Efektivitas Bio Herbisida (Theobroma cacao L) Dengan Beberapa Tingkat Kematangan Fermentasi Terhadap Pengendalian Gulma di Perkebunan Kelapa Sawit (Elaeis guineensisJacq)

\section{Tingkat Keracunan Gulma}

Tingkat keracunan gulma mulai diamati pada 1 hingga 7 HSA (Hari Setelah Aplikasi). Tingkat keracunan gulma diamati pada perubahan bentuk dan warna dari bagian gulma yang berubah akibat aplikasi bio herbisida pulp kakao. Hasil pengamatan pengaruh bio herbisida pulp kakao terhadap pengendalian gulma tertera pada Tabel 4.1

Tabel 4.1 Rataan persentase keracunan gulma pada pengamatan ke-1 sampai pengamatan ke-7 HSA (Hari Setelah Aplikasi).

\begin{tabular}{|c|c|c|c|c|c|c|c|c|c|}
\hline \multirow{2}{*}{ PERLAKUAN } & \multicolumn{7}{|c|}{ PENGAMATAN HARI KE $1-7 \mathrm{HSA}(\%)$} & \multirow{2}{*}{ TOTAL } & RATAAN \\
\cline { 2 - 9 } & 1 & 2 & 3 & 4 & 5 & 6 & 7 & 0,00 & 0,00 \\
\hline $\mathrm{K}$ & $0,00 \mathrm{a}$ & $0,00 \mathrm{a}$ & $0,00 \mathrm{~A}$ & $0,00 \mathrm{~A}$ & $0,00 \mathrm{~A}$ & $0,00 \mathrm{a}$ & 0,00 & 0,00 \\
\hline $\mathrm{MI}$ & $15,67 \mathrm{~b}$ & $21,67 \mathrm{~b}$ & $26,00 \mathrm{~B}$ & $19,00 \mathrm{~B}$ & $15,67 \mathrm{~B}$ & $12,67 \mathrm{~b}$ & 9,33 & 120,01 & 17,14 \\
\hline $\mathrm{M} I \mathrm{I}$ & $19,67 \mathrm{bc}$ & $24,33 \mathrm{bc}$ & $30,00 \mathrm{BC}$ & $26,67 \mathrm{BCD}$ & $19,33 \mathrm{BCD}$ & $16,67 \mathrm{bcd}$ & 12,67 & 149,34 & 21,33 \\
\hline MIII & $23,00 \mathrm{bcd}$ & $27,33 \mathrm{bcd}$ & $31,00 \mathrm{BCD}$ & $22,67 \mathrm{BC}$ & $19,00 \mathrm{BC}$ & $12,67 \mathrm{bc}$ & 8,33 & 144,00 & 20,57 \\
\hline TOTAL & 58,34 & 73,33 & 87,00 & 68,34 & 54,00 & 42,01 & 30,33 & 413,35 & \\
\hline RATAAN & 14,59 & 18,33 & 21,75 & 17,09 & 13,50 & 10,50 & 7,58 & & 14,76 \\
\hline
\end{tabular}

Pada Tabel 4.1 dapat dilihat dari hasil pengamatan menunjukkan bahwa perlakuan bio herbisida pulp kakao berpengaruh nyata pada pengamatan yang dilakukan setiap hari selama 7 hari terhadap persentase keracunan gulma. Pada pengamatan ke-1, 2, dan 6 HSA menunjukkan pengaruh nyata padA persentase tingkat keracunan gulma sedangkan pada pengamatan ke-3, 4, dan 5 HSA menunjukkan pengaruh sangat nyata pada persentase tingkat keracunan gulma. Persentase nilai keracunannya semakin meningkat pada hari ke-1 hingga hari ke-3 HSA dan mengalami penurunan pada hari ke-4 hingga hari ke-7 HSA. Berdasarkan pengamatan visual keracunan yang ditimbulkan terlihat efek bakar dan bercak-bercak pada gulma dan terlihat menurunnya daya racun sejalan dengan bertambahnya umur pengamatan gulma (Gambar dapat dilihat dalam lampiran). Berdasarakan gejala dan sifat umum yang ditunjukkan gulma setelah diaplikasikan bio herbisida pulp kakao, kemampuan bio herbisida pulp kakao hampir sama dengan herbisida kontak, herbisida kontak sistem kerjanya langsung mematikan jaringan atau bagian gulma yang terkena larutan herbisida. 2-3 jam setelah disemprot gulma sudah layu dan 2-3 HSA kemudian mengalami tingkat keracunan tertinggi. Dan pada 4-7 HSA tingkat keracunan menurun dan gulma akan segera pulih dan tumbuh kembali. Bagian tumbuhan dibawah tanah seperti akar atau akar rimpang tidak terpengaruhi sehingga dapat kembali pulih karena proses kerja pada herbisida ini pun sangat cepat. Respon dari gulma yang terdapat pada tiap-tiap plot setelah diaplikasikan cairan fermentasi pulp kakao berbeda-beda untuk tiap jenisnya. Sembodo (2010) menyatakan bahwa gulma dari spesies yang samapun kadangkala memberikan respon yang berbeda terhadap herbisida tertentu. Apalagi antar jenis gulma walaupun dalam satu golongan tertentu, respon yang ditunjukkan sering berbeda. Berdasarkan rataan persentase keracunan gulma dapat disimpulkan bahwa perlakuan bio herbisida pulp kakao pada MI,MII, dan MIII saangat berbeda dibandingkan dengan K. MIpada pengamatan ke-1 mengalami keracunan sedang dengan persentase sebesar $15,67 \%$, kemudian mengalami kenaikan menjadi keracunan berat pada pengamatan ke-2 dan ke-3 dengan persentase sebesar $21,67 \%$ dan 26,00\% dan mengalami penurunan dari pengamatan ke-4 sampai ke-7 menjadi keracunan ringan. MII pada pengamatan ke-1 mengalami keracunan sedang dengan persentase sebesar 19,67\%, kemudian mengalami kenaikan pada pengamatan ke-2 dan ke-3 menjadi keracunan berat dengan persentase sebesar $24,33 \%$ dan $30,00 \%$ dan mengalami penurunan pada pengamatan ke-4 sampai ke-7 
Aulia J, Saroha M, Yasser Subroto G: Efektivitas Bio Herbisida (Theobroma cacao L) Dengan Beberapa Tingkat Kematangan Fermentasi Terhadap Pengendalian Gulma di Perkebunan Kelapa Sawit (Elaeis guineensisJacq)

menjadi keracunan sedang.MIIIpada pengamatan ke-1 dan ke-2 mengalami keracunan berat dengan persentase sebesar $23,00 \%$ dan $27,33 \%$, kemudian mengalami kenaikan pada pengamatan ke-3 menjadi keracunan berat dengan persentase sebesar $31,00 \%$ dan mengalami penurunan pada pengamatan ke 4 sampai ke-7 menjadi keracunan ringan. Pada rataan persentase keracunan gulma pada pengamatan ke-1 sampai pengamatan ke-7 HSA nilai tertinggi tingkat keracunan gulma terdapat pada 3 HSA. Perlakuan yang tertinggi terdapat pada perlakuan MIII yaitu sebesar 31,00\% sedangkan MIIsebesar 30,00\% dan MIsebesar 26,00\%. Untuk lebih jelasnya dapat dilihat melalui Gambar 4.1 di bawah ini.

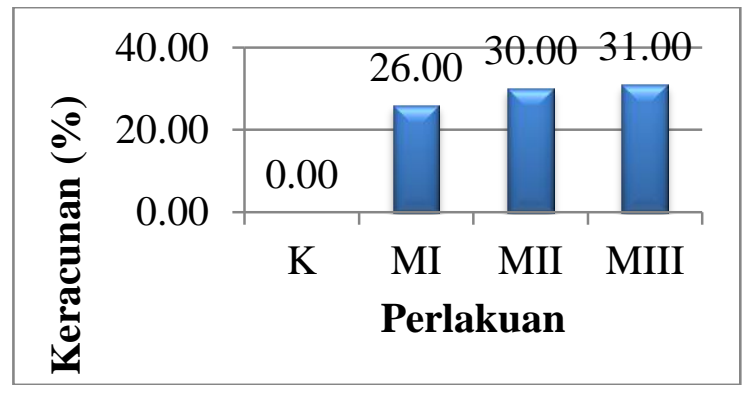

Gambar 4.1 Grafik rataan persentase tingkat keracunan gulma pada pengamatan ke-3 HSA

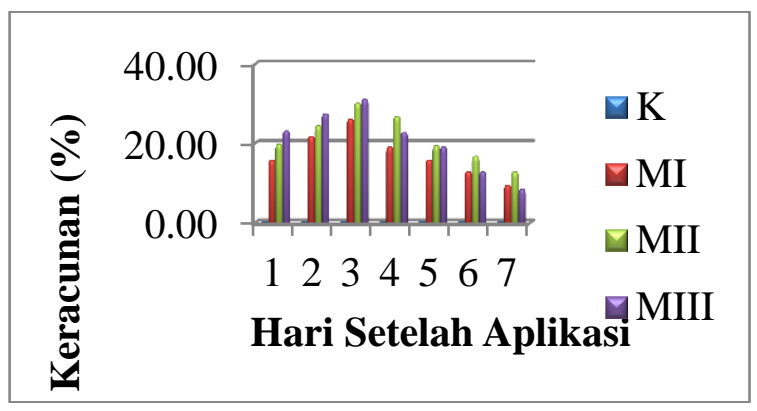

Gambar 4.2 Grafik rataan persentase tingkat keracunan gulma pada pengamatan ke-1 sampai pengamatan ke-7( HSA)

Pada gambar 4.2 dapat dilihat bahwasannya perlakuan MIII lebih baik dibandingkan MI dan MII. Hal ini disebabkan karena lama fermentasi mempengaruhi besarnya kandungan asam cuka untuk tiap perlakuan. Kandungan asam cuka pada fermentasi 3 minggu lebih tinggi dibandingkan fermentasi 1 dan 2 minggu. Perbedaan tingkat keracunan dapat dilihat dari bercak-bercak dan terbakarnya bagian gulma yang bersifat kontak dengan kandungan asam cuka pada fermentasi masing-masing perlakuan. Hal ini sesuai dengan (Suryani $\mathrm{W}, 1991)$ yang menyatakan bahwa pemilihan jenis herbisida yang tepat harus diikuti dengan cara-cara aplikasi yang benar, sehingga akan dicapai hasil pengendalian yang efektif.

\section{KESIMPULAN}

Berdasarkan hasil penelitian dari aplikasi fermentasi limbah cair pulp kakao dapat disimpulkan bahwa :

1. Perlakuan bio herbisida pulp kakao berpengaruh nyata terhadap persentase keracunan gulma.

2. Perlakuan fermentasi minggu ke-3 (MIII) memiliki persentase tingkat keracunan lebih tinggi pada 3 HSA dengan tingkat keracunan mencapai 31,00\%. 
Aulia J, Saroha M, Yasser Subroto G: Efektivitas Bio Herbisida (Theobroma cacao L) Dengan Beberapa Tingkat Kematangan Fermentasi Terhadap Pengendalian Gulma di Perkebunan Kelapa Sawit (Elaeis guineensisJacq)

Daya racun yang ditimbulkan oleh bio herbisida pulp kakao bersifat kontak karena terlihat dari bercak-bercak dan terbakarnya bagian gulma yang terkena fermentasi limbah cairan pulp kakao

\section{DAFTAR PUSTAKA}

Away, Y. 1985. Evaluasi Pengaruh Beberapa Marga Mikroorganisme pada Fermentasi Biji Kakao Terhadap Mutu Cita rasa Indeks Fermentasi. Tesis. ITB. Bandung.

Djojosumarto, Panut. 2008. Panduan lengkap pestisida dan aplikasi. PT Agromedia Pustaka. Jakarta.

Effendi, M.S. 2002. Kinetika fermentasi asam asetat (vinegar) oleh bakteri Acetobacter aceti B127 dari etanol hasil fermentasi limbah cair pulp kakao. Jurnal Tekno dan Industri Pangan Vol 13 (2) : 125 - 135.

Fardiaz, Srikandi. 1992. Mikrobiologi pangan 1. Gramedia Pustaka Utama. Jakarta.

Genowati, I dan U. Suwahyono. 2008. Prospek Bioherbisida sebagai Alternatif Penggunaan Herbisida Kimiawi. Direktorat, TAB, BPP Teknologi. Jakarta.

Hartoto, L. 1991. Petunjuk Laboratorium Teknologi Fermentasi. IPB : Pusat Antar Universitas Bioteknologi. Bogor.

Jhonny, Martin. 2006. Dasar-dasar Mata Kuliah Gulma. Jurusan Biologi. Fakultas Matematika dan Ilmu Pengetahuan Alam. Universitas UNDAYA.

Komisi Pestisida. 2000. Pestisida Untuk Pertanian dan Kehutanan. Departemen Pertanian. Koperasi Daya Guna. Jakarta.

LPP. 2000. Buku Pintar Mandor Seri Budidaya Tanaman Kelapa Sawit. Yogyakarta.

Lubis, A.U. 2008. Kelapa Sawit (Elaeis guineensis Jacq.) di Indonesia. Edisi Revisi 2. Pusat Penelitian Kelapa Sawit Medan.

Moenandir, Jody. 1993. Pengantar Ilmu dan Pengendalian Gulma. Buku 1. PT Raja Grafindo Persada. Jakarta.

Nasution, Z., M.C. Wahyudi dan S.L. Betty. 1985. Pengolahan Cokelat. Agroindustri. IPBpress. Bogor.

Purawisastra S, Gumbira-Sa'id E, Doelle HW. 1994. Peningkatan Etanol Hasil Fermentasi Zymomonas Mobalis dengan Enzim Invetase. J.Mikrobiol Inones. Vol 2:31 - 35.

Sastroutomo.S.S. 1990. Ekologi Gulma. PT gramedia Putaka Utama. Jakarta.

Sembodo, D. R. J. 2010. Gulma Dan Pengelolaannya. Graha Ilmu Yogyakarta.

Sukman, Yernelis dan Yakup. 2002. Gulma dan Teknik Pengendaliannya. PT. Rajagrafindo Persada. Jakarta.

Sunarto, H. 1992. Cokelat Budidaya, Pengolahan Hasil, dan Aspek Ekonominya. Kanisius. Yogyakarta.

Suryani, w. 1991. Studi Efektifitas Beberapa Perlakuan Herbisida Dengan DuaAlat Semprot Untuk Pengendalian Gulma Utama Di Jalur Tanaman KaretMenghasilkan. Jurusan Budidaya Pertanian. Fakultas Pertanian. Institut Pertanian Bogor 